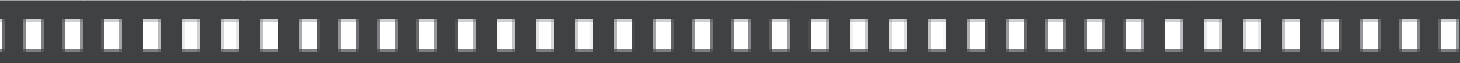 Enchentes no Nordeste: a humanização da notícia na cobertura fotográfica da Folha de S. Paulo

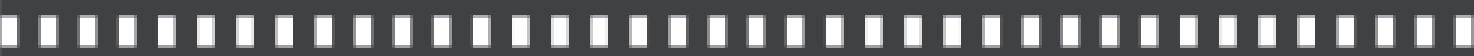

Carolina Zoccolaro Costa Mancuzo

Renato Pandur de Maria

Paulo César Boni 


\title{
Enchentes no Nordeste: a humanização da notícia na cobertura fotográfica da Folha de S. Paulo*
}

\author{
Flood in Northeast: humanizing news on photo \\ coverage at Folha de S. Paulo
}

\author{
CarolinaZoccolaro Costa Mancuzo ** \\ Renato Pandur de Maria *** \\ Paulo César Boni ****
}

\begin{abstract}
Resumo: Este artigo analisa as fotografias da cobertura das enchentes no nordeste brasileiro, tomadas pelo repórter fotográfico Fernando Donasci e publicadas na Folha de S. Paulo, de 18 a 25 de maio de 2009. Seu objetivo é avaliar, por meio da desconstrução analítica, proposta por Boni (2000), qual a intencionalidade do fotógrafo ao capturar cada uma das imagens analisadas. A desconstrução analítica - identificação e conceituação dos recursos técnicos e dos elementos da linguagem fotográfica - possibilita se aproximar da intencionalidade de comunicação do emissor no ato fotográfico. Com a análise, ficou fortemente conotado que Fernando Donasci utilizou cores quentes e valorizou o elemento humano na busca pela humanização da noticia.
\end{abstract}

Palavras-Chave: Folha de S.Paulo; Fernando Donasci; fotojornalismo; desconstrução analítica; humanização da notícia.

\begin{abstract}
This article analyses the photographic coverage of northeast Brazilian coast flood done by the photographic reporter Fernando Donasci and published by the newspaper Folha de S. Paulo, from May $18^{\text {th }}$ to $25^{\text {th }}$. It aims to evaluate the photographer intentionality when capturing each image using an analytical deconstruction proposed by Boni (2000). The analytical deconstruction-identification and conceptualization of technical resources and elements of photographic language - enables the approach of communication intentionality on the photographic act. Along with the analysis, it was strongly connoted that Fernando Donasci used strong colors and appreciated the human element on the search for humanizing news.
\end{abstract}

Key-words: Folha de S.Paulo; Dernando Donasci; photojournalism; analytical deconstruction; humanizing news.

\footnotetext{
* Trabalho apresentado, com pequenas adequações, no Grupo de Pesquisa de Fotografia do IX Encontro dos Grupos de Pesquisas em Comunicação, evento do XXXII Congresso Brasileiro de Ciências da Comunicação (Intercom), realizado em Curitiba (PR), de 4 a 7 de setembro de 2009. ** Graduada em Comunicação Social - Habilitação Jornalismo pela Universidade do Oeste Paulista de Presidente Prudente (SP). Especialista em Agronegócios pelas Faculdades Integradas "Antônio Eufrásio de Toledo", de Presidente Prudente. Mestranda em Comunicação pela Universidade Estadual de Londrina. Professora e coordenadora do curso de Comunicação Social da Universidade do Oeste Paulista, de Presidente Prudente.

*** Graduado em Comunicação Social - Habilitação Jornalismo pela Universidade do Oeste Paulista de Presidente Prudente (SP). Estudante especial do Mestrado em Comunicação da Universidade Estadual de Londrina (PR). Professor do curso de Comunicação Social da Universidade do Oeste Paulista (SP).

**** Doutor em Ciências da Comunicação pela Universidade de São Paulo (ECA/USP). Coordenador do Mestrado em Comunicação da Universidade Estadual de Londrina (PR).
} 


\section{Introdução}

O fotojornalismo, desde sua origem, trabalha para atender aos mais diversos interesses da sociedade, sejam eles "tarefas estéticas, políticas, culturais, econômicas e ideológicas" ou outras, como afirma Sousa (2004, p.223). Isso ficou evidente em praticamente todos os momentos da história, pós-fotografia. Relembrando o Farm Security Administration (FSA), Sousa (2004, p.110) afirma que:

[...] de 1935, e até 1942, desenvolveu-se o projeto fotodocumental conhecido por Farm Security Administration (FSA). Este projeto procurou, especificamente, retratar os resultados das políticas do New Deal do presidente Roosevelt [...] e teve uma grande repercussão porque as fotografias foram amplamente divulgadas na imprensa, em livros e em exposições.

Esta realidade não é diferente nos dias atuais. Nos meses de abril e maio de 2009, o nordeste brasileiro sofreu com chuvas intensas, que provocaram enchentes e causaram estragos em 13 estados. Mais de 300 mil pessoas ficaram desabrigadas. O Ceará não registrava tamanha precipitação havia 25 anos; o Maranhão foi o mais afetado. A falta de energia elétrica e de água potável fez a vida dos desabrigados ficar em condições extremamente precárias.

Num primeiro momento, a imprensa brasileira noticiou a tragédia com certo distanciamento dos fatos. Conforme os problemas foram se agravando na região, os leitores da Folha de S. Paulo cobraram uma atitude mais contundente do jornal, que resultou na publicação de uma crítica de seu ombudsman (jornalista contratado para fiscalizar as coberturas do jornal, priorizando as necessidades do leitor), Carlos Eduardo Lins da Silva, na edição de 17 de maio, na qual questionava a diferença de tratamento e de espaço em comparação à cobertura de tragédia semelhante, no estado de Santa Catarina, em novembro de 2008.

Depois disso, a redação enviou ao nordeste uma equipe de São Paulo, para fazer uma cobertura mais próxima do caso. O repórter 
fotográfico destacado para cobrir a tragédia foi Fernando Donasci, que trabalha no jornal desde 2005 e teve a experiência de acompanhar também o drama de Santa Catarina. Sua primeira imagem sobre as enchentes foi publicada com destaque na primeira página do dia 18 de maio, dia seguinte à crítica do ombudsman. Em oito dias, a cobertura rendeu ao fotógrafo três capas, todas muito comentadas pelos leitores.

\section{Recursos técnicos, linguagem fotográfica e geração de sentido}

A análise de uma fotografia pode ser efetuada por diversas metodologias. Poucas, porém, são realizadas em nível de primeiro, ou seja, avaliando o momento da captura da imagem e a intencionalidade de comunicação do fotógrafo.

Três elementos são, pois, essenciais para a realização de uma fotografia: o assunto, o fotógrafo e a tecnologia. São estes os elementos constitutivos que lhe deram origem através de um processo, de um ciclo que se completou no momento em que o objeto teve sua imagem cristalizada na bidimensão do material sensível, num preciso e definido espaço e tempo. (KOSSOY, 1989, p.23, grifos do autor).

Com a proposta de Kossoy (1989), a análise abrange todos os elementos da fotografia: o assunto, o emissor e a tecnologia utilizada. Este artigo, no entanto, propõe-se a analisar o ponto de vista do emissor da informação, considerando, além da tecnologia, também os elementos da linguagem fotográfica utilizada. Para tanto, adota a proposta metodológica da desconstrução analítica proposta por Boni (2000). De acordo com o autor, antes do ato fotográfico, o fotógrafo constrói um significado em sua mente. Ao escolher o ângulo, plano, enquadramento ou quaisquer outros elementos componentes da linguagem fotográfica, 
ele transforma seu significado em significantes para os leitores. Cada pessoa, ao fazer a leitura desta imagem, e de acordo com seu repertório pessoal, construirá o seu próprio significado. Isso ocorre porque "a fotografia é uma manifestação de linguagem. E por ser uma mensagem de códigos abertos e contínuos, permite múltiplas leituras". (CAMPOS; BONI, 2005, p.57).

Os leitores de uma imagem, segundo Kossoy (1989, p.23),

[...] reagem de formas totalmente diversas - emocionalmente ou indiferentemente - na medida em que tenham ou não alguma espécie de vínculo com o assunto registrado, na medida em que reconheçam ou não aquilo que vêem (em função do repertório cultural de cada um), na medida em que encarem com ou sem preconceitos o que vêem (em função das posturas ideológicas de cada um).

Boni (2000, p.111) complementa: "Emissor da mensagem fotográfica em primeira instância, o fotógrafo manifesta sua intencionalidade através dos recursos que the são peculiares: os técnicos e os da linguagem fotográfica." Assim, para aferir a mensagem fotográfica, de forma a se aproximar da intencionalidade do fotógrafo, é preciso primeiro fazer uma leitura técnica da imagem. Em seguida, identificar os elementos da linguagem fotográfica utilizados para transmitir a informação. A leitura atenta de uma imagem permite deduções sobre a intencionalidade de comunicação do fotógrafo, ou seja, uma aproximação o mais fiel possível do que o fotógrafo tinha em mente e queria traduzir para seus leitores no momento do clique.

Contudo, a certeza sobre a intenção do fotógrafo só se tem a partir do momento que ele a declare em entrevista ou em algum documento escrito. Assim, para aferir se Fernando Donasci foi eficiente ao transmitir informações com as imagens tomadas no nordeste, após a análise das imagens o próprio fotógrafo foi entrevistado por e-mail, em duas ocasiões (dias 22 e 27 de junho de 2009), para falar de suas fotografias. Suas impressões foram incorporadas às análises. 
Até ser publicada, a fotografia passa por diversas mãos e recursos de edição. Consequentemente, a geração de sentido primeira, a do fotógrafo, pode sofrer influências do editor e da linha editorial do jornal. Ao analisar o processo de edição de fotografias, Moretzsohn (2002, p.8889) constata que

[...] a ironia, o duplo sentido ou a sedimentação de consensos, com conseqüências éticas relevantes. A simples seleção de determinadas fotos para publicação ou a relação estabelecida entre elas na edição sugere a busca desses efeitos. [...] Mais interessante ainda é ver o tipo de relação que se cria entre texto e foto, perceptível em qualquer matéria que utilize esses dois elementos.

A proposta deste artigo, analisando os recursos técnicos e a linguagem fotográfica utilizada por Donasci na captura das imagens, tem muito a ver com a ideia de Moretzsohn (2002), principalmente no que se refere à seleção das fotografias para publicação pelo veículo e na relação por elas ou com elas estabelecidas para a geração de sentido.

\section{Análise das imagens}

Oito fotografias publicadas pela Folha de S. Paulo, entre os dias 18 e 25 de maio de 2009, foram selecionadas para a análise neste artigo. Todas são de Fernando Donasci e três foram destacadas, em dias alternados, na primeira página do jornal. Destas, duas reportavam a situação no Maranhão e uma no Piauí.

No primeiro dia, 18 de maio, foram publicadas duas fotografias no jornal, ambas coloridas: uma de capa e uma interna. Na capa, a fotografia está localizada na dobra superior, parte privilegiada da edição, como a principal do dia. Nela (Figura 1) há uma mãe que contempla seu filho em uma rede. Percebe-se um véu, utilizado para proteger o bebê 
dos mosquitos, e velas acesas. O local, conforme informa o texto, é um hospital abandonado, improvisado como abrigo, na cidade de Trizidela do Vale (MA). Como não havia energia elétrica, segundo a legenda, as velas iluminavam o ambiente.

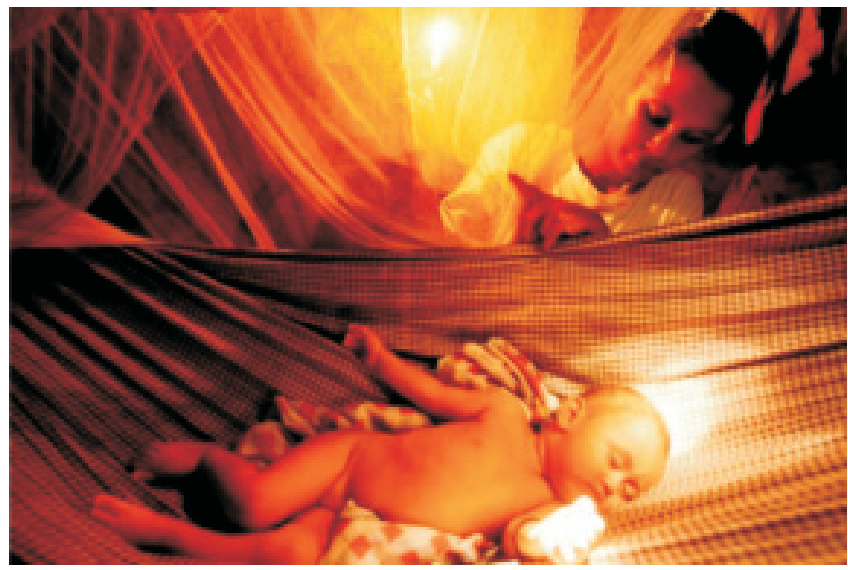

Figura 1 - Mãe vela o sono do filho

Fotografia: Fernando Donasci

Fonte: Folha de S.Paulo - capa-18/05/2009

O plano de tomada é o médio, com corte americano, que valoriza a ação do sujeito. $\mathrm{O}$ ângulo é o linear, que fica de frente para o tema, na mesma altura dos olhos. A fotografia está centralizada. As cores quentes, normalmente utilizadas para transmitir ação, neste caso representam o drama. Segundo Donasci, "a cor quente é um estilo que gosto de mostrar minhas imagens, oflash me incomoda um pouco no fotojornalismo, porque as pessoas acabam assustando com o disparo da luz e perdem a naturalidade". ${ }^{1}$ A iluminação da imagem é feita por uma luz de vela atrás da cortina e, provavelmente, com uma luz de preenchimento direcionada ao bebê.

Neste dia, segundo a reportagem, fotógrafo e repórter passaram a noite no abrigo improvisado, no qual as mães não dormiam e se revezavam

\footnotetext{
${ }^{1}$ Fernando Donasci. Entrevista concedida à Carolina Z. C. Mancuzo por e-mail, em 22/06/2009.
} 
para espantar mosquitos. As paredes viraram mictórios e as velas acesas para santos em altares iluminavam também o jantar. Na imagem, a criança dorme alheia ao drama decorrente da enchente. A rede mais parece uma manjedoura. Dormia sem roupa e sem coberta por causa do calor.

[...] a criança dormindo também tem a leitura de um sono profundo querendo dizer que as pessoas poderiam morrer se as condições não fossem modificadas naquele local, mas por outro lado com a inocência de uma criança dormindo parecendo o menino Jesus. A vela na mão era pra ter mais destaque para lembrar essa ideia de velório. $^{2}$

Na primeira página, percebe-se que a edição optou por uma imagem humanizada em detrimento dos estragos provocados pela enchente. Esse tipo de imagem chama mais a atenção do leitor, pois trata o ser humano individual, enfrentando problemas coletivos. Traz força ao drama vivido. O próprio fotógrafo concorda: "O elemento humano é o mais importante da história. A tragédia de modo geral é vista sim, mas quando o espaço é curto, como jornal impresso, a preferência é do sofrimento do ser humano."’3

A segunda imagem (Figura 2) da cobertura foi publicada numa página interna, a $\mathrm{C} 4$ do caderno Cotidiano, também do dia 18 de maio. Apesar de estar em página ímpar, é colorida e ocupa boa parte da dobra superior do jornal, local considerado privilegiado. Nela aparece a dona Maria do Nazaré Soares, de 61 anos, segundo a legenda, agachada, segurando uma vela, olhando para seus filhos e netos dormindo no abrigo. Quatro crianças dormem sobre espumas, que fazem as vezes de colchão. O cenário demonstra o improviso no alojamento, com espumas e panos espalhados pelo chão, um fogão e uma mesa com utensílios. No fundo aparecem as pernas de outras três pessoas.

\footnotetext{
${ }^{2}$ Fernando Donasci. Entrevista concedida à Carolina Z. C. Mancuzo, por e-mail, em 27/06/2009.

${ }^{3}$ Fernando Donasci. Entrevista concedida à Carolina Z. C. Mancuzo, por e-mail, em 22/06/2009.
} 


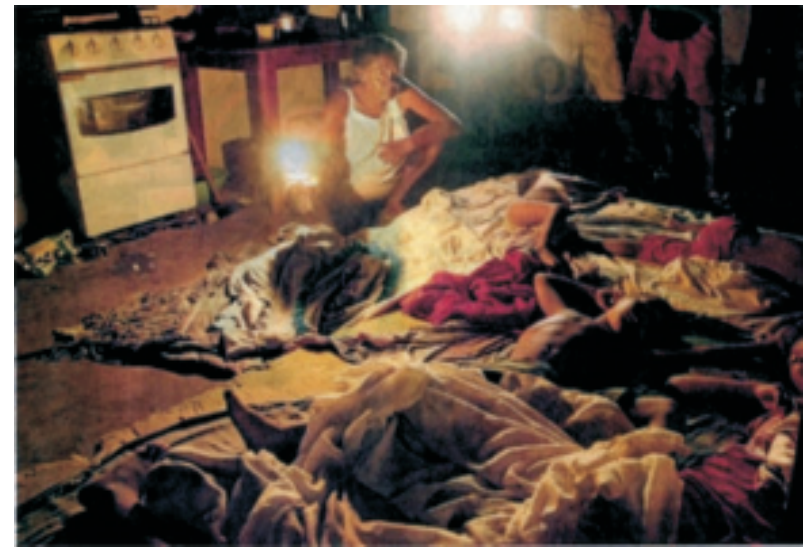

Figura 2 - Maria do Nazaré Soares e seus filhos no abrigo improvisado, em Trizidela do Vale

Fotografia: Fernando Donasci

Fonte: Folha de S.Paulo, caderno Cotidiano, página C4, 18/05/2009

A mãe, com a feição sofrida e desconfiada, observa as crianças e demonstra preocupação. Não se vê alimentos, o que causa a sensação de escassez. A falta de energia elétrica deve fazer com que os alimentos não tenham onde ser conservados adequadamente. Provavelmente, as sobras - se é que havia - eram descartadas. As três pessoas atrás da mulher ficam à espera para poder dormir. Fazem esquema de revezamento, conforme a legenda.

Mais uma vez, o fotógrafo utiliza um exemplo particular, da precariedade de uma família, para representar o todo. O olhar da mulher, que encara a lente do fotógrafo, conota que ela está insatisfeita, preocupada e aflita com a situação. Ao contrário da fotografia da capa, não há valorização da plasticidade da imagem. É a dura realidade das pessoas atingidas pelas enchentes.

A intencionalidade de comunicação do repórter fotográfico ao docu-mentar alguma ocorrência para o veículo em que trabalha é manifesta pela forma como compõe a mensagem fotográfica. Ele se sente tão responsável pela informação quanto o repórter de texto. Sente a necessidade de traduzir para o leitor, através de 
imagens, o que testemunhara por estar presente ao local do ocorri-do. A intencionalidade se evidencia em razão de ele primeiro construir o seu significado pessoal do fato e depois, utilizando-se dos recursos técnicos e dos elementos da linguagem fotográfica, tentar traduzi-lo para o leitor. (BONI, 2005, p.87).

A segunda vez que o jornal estampou uma fotografia da enchente na capa foi no dia 24 de maio, domingo. Neste dia, foram publicadas três imagens: uma na capa, uma como chamada interna (na capa do caderno Cotidiano) e outra na reportagem. Duas são coloridas e uma em preto e branco.

$\mathrm{Na}$ imagem publicada na capa (Figura 3), vê-se uma criança tomando banho "de caneca" dentro de um balde, que está ao lado de uma cadeira de fios. O balde está sobre um bloco de concreto; abaixo vê-se uma caixa d'água fechada.

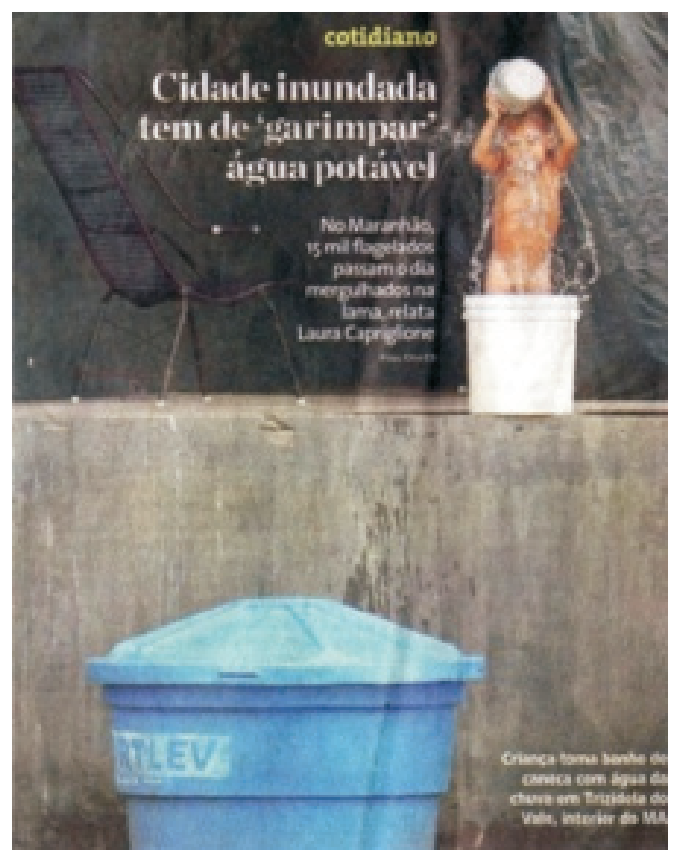

Figura 3 - Criança tomando banho "de caneca" Fotografia: Fernando Donasci

Fonte: Folha de S.Paulo-capa-24/05/09 
O plano é o médio, usado com a finalidade de interagir o sujeito ao ambiente. $\mathrm{O}$ ângulo de tomada é um leve mergulho, se analisado do centro da imagem, devido à inclinação do chão. Este ângulo normalmente é utilizado para inferiorizar algum elemento, o que não acontece nesta fotografia, já que é muito sutil. A fotografia foi tomada na vertical, o que proporciona uma sensação de movimento, ação. A regra dos terços está com os pontos de ouro valorizados: menino no balde, cadeira e caixa d'água. Além disso, o posicionamento dos elementos cria o formato de um triângulo, que garante a circularidade no olhar, levando os olhos a seguir uma sequência horária dos elementos. O uso da teleobjetiva tira a sensação de profundidade de campo e achata os planos. Há um contraste evidente do bloco de concreto com o fundo da parede superior.

A fotografia, por si só, não demonstra o problema de enchentes e falta de água vividos no Maranhão. Porém, existem vários significantes que podem conotar esta geração de sentido. A caixa d'água fechada, próxima ao garoto que toma banho em um balde, pode sugerir escassez de água. A posição da criança, acima da caixa d'água, porém tomando banho no balde, com água de chuva (conforme a legenda), passa a ideia de que não há água. Para ela, a água está fechada; ela parece não ter direito à água. A cadeira vazia, valorizada no enquadramento, embora com pouco contraste, posto que ela é escura e o fundo também, sugere solidão: uma criança que precisa se virar sozinha. Não há adultos naquela cadeira para cuidar dela e lhe dar banho, ao menos não captados pela fotografia. $\mathrm{O}$ fundo escuro causa a sensação de tristeza, solidão, desamparo. Donasci concorda: "No mesmo fotograma eu tinha todos esses pontos positivos para uma boa foto, o efeito da água caindo na cabeça dele e a cadeira vazia traz uma leitura de solidão e abandono." ${ }^{\prime 4}$

\footnotetext{
${ }^{4}$ Fernando Donasci. Entrevista concedida à Carolina Z. C. Mancuzo, por e-mail, em 27/06/2009.
} 
[...] fatos que denunciam toda uma situação dramática de sofrimento, miséria, dor e crueldade podem ser captados de forma harmoniosa, de acordo com o ângulo de tomada, descontextualizados de seu entorno, 'amenizados' em seus detalhes e, finalmente, esvaziados nas manchetes, legendas e textos que os acompanham. (KOSSOY, 2007, p.105).

Algo importante a se destacar nessa imagem é a edição feita pelo jornal. Moretzsohn (2002, p.88-89) ressalta que o título, a legenda e os elementos da página são importantes na geração de sentido da imagem. Sozinha, ela não dimensiona ou localiza o problema. Mas quando associada ao título 'Cidade inundada tem de 'garimpar' água potável”, à linha-fina "No Maranhão, 15 mil flagelados passam o dia mergulhados na lama, relata Laura Capriglione" e à legenda "Criança toma banho de caneca com água da chuva, em Trizidela do Vale, interior do MA", a leitura ganha um sentido mais completo. A localização na página não é tão valorizada, pois está na parte inferior da dobra. Embora, mesmo dobrado, seja possível ver um pedaço da imagem, despertando a curiosidade do leitor em ver o restante.

A imagem da capa do caderno Cotidiano do mesmo dia está em uma chamada de caixa (jargão jornalístico utilizado para especificar chamadas no alto da página, ao lado do logotipo do caderno). $\mathrm{Na}$ imagem (Figura 4), há uma parede com várias torneiras e muita umidade, perceptível pela alta concentração de lodo. Em segundo plano, desfocado, é possível ver vários galões de água sendo cheios. Há também um senhor olhando em direção ao fotógrafo ou à água que cai. Mais ao fundo, outras pessoas buscam seus galões. No canto inferior direito vê-se parte de um engradado de garrafas, que possivelmente serão ou foram enchidas com esta água.

O plano utilizado é o médio, que tem por finalidade interagir o sujeito ao ambiente. O ângulo de tomada é o normal ou linear, de frente para o tema, na mesma altura dos olhos. $\mathrm{O}$ fotógrafo abriu uma perspectiva na diagonal, criando a impressão de um número considerável de torneiras abertas. Houve a valorização do primeiro 
plano, onde se pode ver com nitidez uma torneira aberta, numa parede cheia de lodo. Nesta fotografia, inclusive, a cor fez a diferença, ajudando na percepção de textura na parede e dando a clara sensação de umidade no local, que seria mantida, mesmo que a torneira estivesse fechada. Percebe-se também a seletividade de foco: ao focar o primeiro plano (torneira aberta) e desfocar o fundo (pessoas buscando água e homem vendo a água cair), o fotógrafo priorizou a imagem da água. Mesmo assim não desvalorizou ou ignorou o elemento humano, pois chama a atenção no enquadramento. A regra dos terços foi utilizada e nela foram valorizados a torneira e o homem, o que demonstra, novamente, a importância da humanização da notícia. O fotógrafo poderia, caso quisesse chamar a atenção apenas para a água caindo, fechar a imagem na torneira, em primeiro plano, mas optou pelo plano médio, colocando o homem num ponto áureo da regra dos terços.

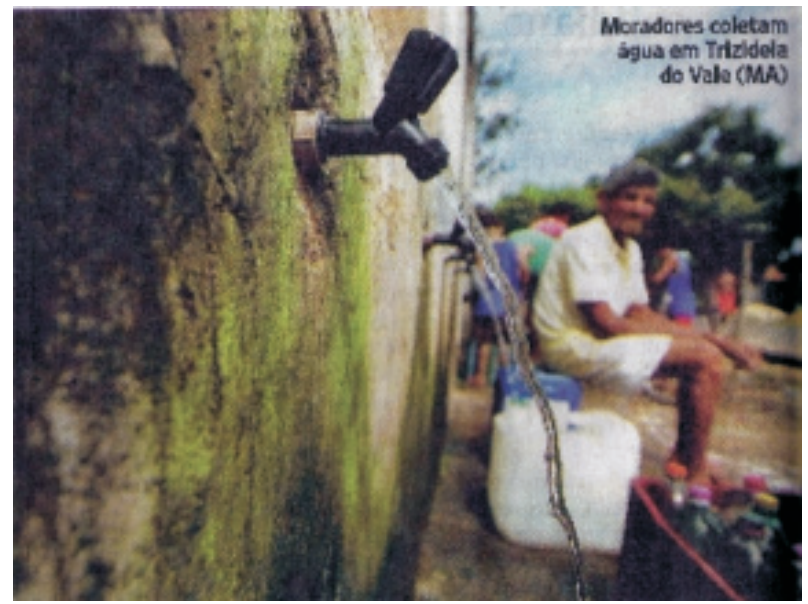

Figura 4 - População busca água potável em bebedouros públicos Fotografia: Fernando Donasci

Fonte: Folha de S.Paulo - página C1 - 24/05/2009

A primeira impressão que se tem ao olhar a imagem isoladamente é o desperdício de água. Os galões sendo cheios não se destacam no primeiro plano, portanto, demoram mais para serem notados. $\mathrm{O}$ homem que olha para o fotógrafo mais parece olhar para o mesmo ponto salientado por 
ele: a torneira e a água. Quando a imagem é associada aos elementos de edição do jornal (legenda e chamada), compreende-se melhor a intencionalidade do fotógrafo. Nesta fotografia, Donasci afirma que quis "mostrar o sumiço da água ou a dificuldade de se ver água potável na região". A fotografia está localizada na página C4 do caderno Cotidiano.

A imagem em preto e branco (Figura 5) mostra o reflexo de uma mulher na água de uma caixa d'água.

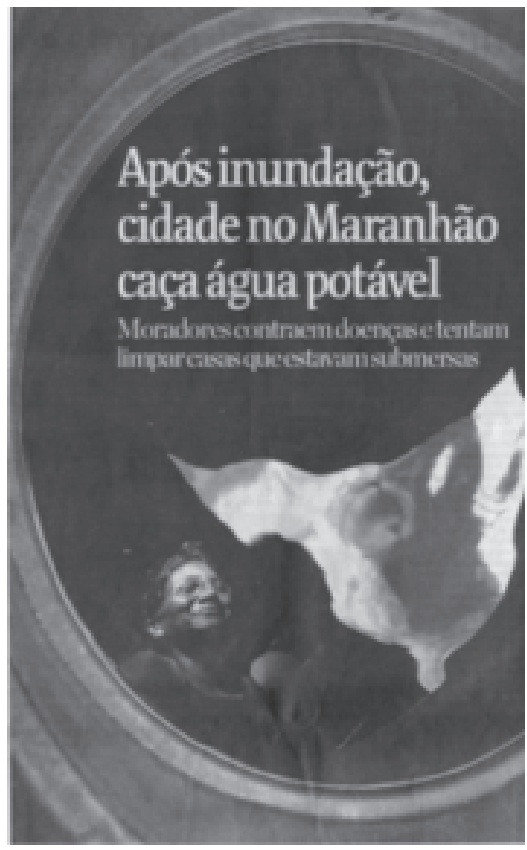

Figura 5 - Rutelene Mota Souza tem rosto refletido em água de caixa d'água Fotografia: Fernando Donasci

Fonte: Folha de S.Paulo - página C4-24/05/2009

A fotografia foi tomada em primeiro plano ou plano de detalhe. Não existe fronteira formal que delimite esses planos. Há autores que a entenderiam como primeiro plano, por isolar a caixa d'água do ambiente. Outros diriam ser um plano de detalhe, pois não apresenta

\footnotetext{
${ }^{5}$ Fernando Donasci. Entrevista concedida à Carolina Z. C. Mancuzo, por e-mail, em 27/06/2009.
} 
a caixa d'água como um todo. $\mathrm{O}$ ângulo de tomada, em relação à posição do fotógrafo, é de mergulho. Porém, em relação ao elemento fotografado, a mulher que aparece no reflexo da água, é de contramergulho, pois ela foi pega de baixo para cima. Esse ângulo é utilizado para valorizar o elemento fotografado, o que não acontece neste caso. Nos pontos áureos da fotografia se destacam: a mulher refletida e os contornos da caixa d'água. A fotografia foi tomada na vertical, o que caracteriza movimento, mas nesta imagem foi usado apenas por ser o melhor enquadramento para a caixa d'água.

A imagem em preto e branco normalmente traz mais drama à fotografia. Neste caso, ela foi utilizada em função da localização da própria matéria no jornal. O reflexo da mulher olhando para a caixa d'água, apesar de não conotar tristeza, mostra a busca pela água, como se ela estivesse literalmente "caçando" água.

A união dos elementos de edição pode traduzir a intencionalidade existente. Neste caso, o título diz: "Após inundação, cidade no Maranhão caça água potável". E a linha-fina: "Moradores contraem doenças e tentam limpar casas que estavam submersas". A legenda: "Água da chuva acumulada em caixa d'água reflete o rosto de Rutelene Mota Souza, em Trizidela do Vale, no Maranhão". As três informações unidas à mensagem fotográfica dão o sentido de que aquela mulher representa a cidade de Trizidela do Vale, que busca água. Só é possível saber que se trata de uma caixa d'água por causa da legenda. Sem ela o leitor poderia ter a interpretação de que era o reflexo em um balde, em um poço, em qualquer lugar, dado o fechamento do ângulo.

No dia seguinte, 25 de maio, foram publicadas mais três fotografias de Donasci. Uma na capa e duas internas, todas coloridas. No caso da primeira fotografia (Figura 6) há o barro entrelaçado às madeiras, um pedaço de pano sustentando as emendas, um fogão velho, uma jarra com alguns potes, um saco de alimento, telhas que se acomodam a outros pedaços de madeira disformes, duas pessoas na cena com idades diferentes. A criança sem camisa e suja. 


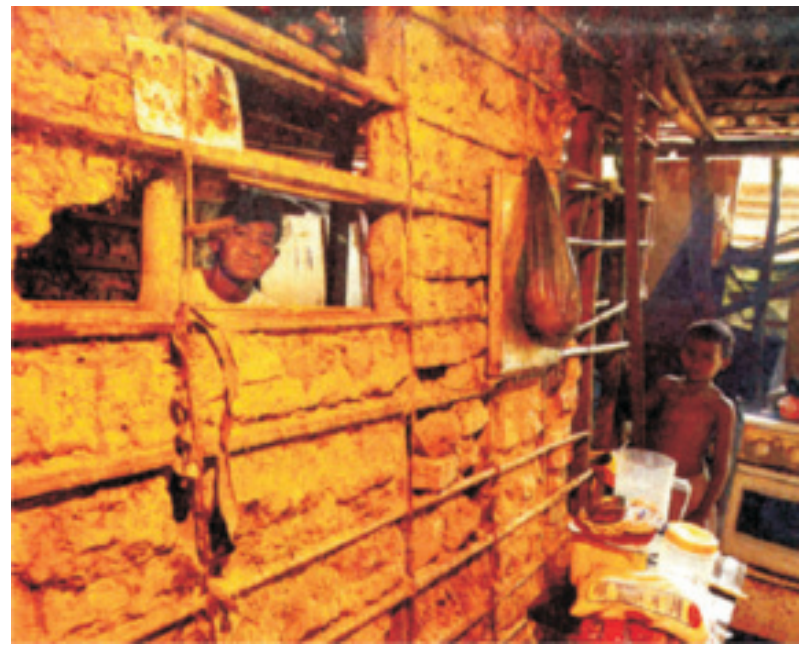

Figura 6 - Regina Lúcia Azevedo e filho em casa que pode ruir Fotografia: Fernando Donasci

Fonte: Folha de S.Paulo - capa-24/05/2009

O plano na fotografia é o médio, que valoriza os elementos fotografados, permitindo um alto poder descritivo. O homem e o ambiente se equilibram na imagem. O ângulo utilizado é o linear, que faz os elementos da cena "olhar" diretamente para o leitor, transmitindo proximidade. A composição é um fator que garante o equilíbrio visual, com a regra dos terços valorizada. As duas pessoas estão posicionadas nos pontos áureos da fotografia. A perspectiva é acentuada e faz com que o leitor "mergulhe" no interior da fotografia, sendo convidado à uma leitura total dos elementos.

No primeiro plano, é possível ver pedaços de madeira maiores, enquanto em segundo plano eles diminuem, o que demonstra a profundidade de campo. Como não há movimento, o fotógrafo optou pelo formato horizontal. A textura é bastante evidente, sendo possível sentila através dos detalhes das paredes de barro.

Outro elemento a ser considerado é a tonalidade, predominantemente amarela. Tecnicamente o amarelo sugere o estímulo visual, fazendo a imagem ganhar atenção pela cor. Neste caso, segundo o fotógrafo, a utilização de tons amarelos foi para aumentar a carga dramática 
da cena. A mulher é limitada por um quadrado semelhante a uma janela, sugerindo esperança ou em um contraponto, a limitação. A criança, em más condições de higiene, retrata o abandono.

Outra fotografia utilizada nesta data foi a da chamada da capa do caderno Cotidiano. Nela (Figura 7), há pedaços de madeira entrelaçados em uma parede de barro seco em ruínas, tijolos no chão, dois buracos na parede, uma criança seminua observando estes buracos, uma parte da perna de um adulto ou de um adolescente, algumas folhagens em um vaso improvisado ao fundo.

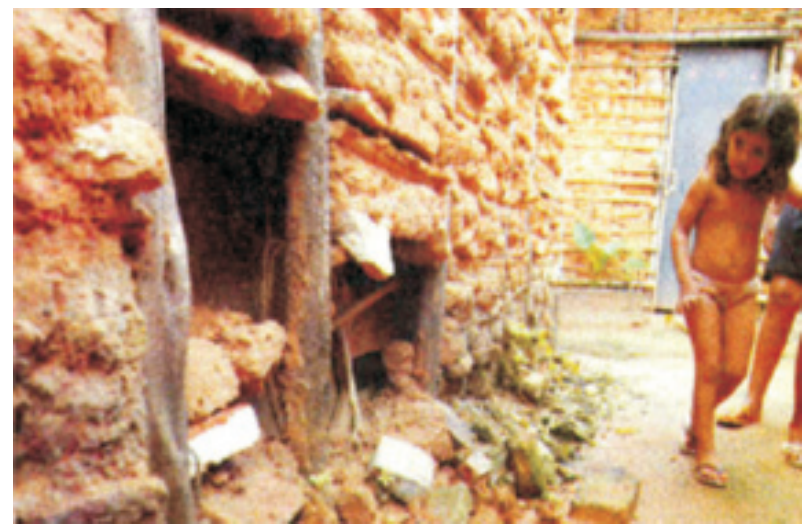

Figura 7 - Criança observa buraco em casa de pau a pique Fotografia: Fernando Donasci

Fonte: Folha de S.Paulo - página C1 - 25/05/2009

Fotografia tomada em plano médio, para interagir sujeito e ambiente. $\mathrm{O}$ ângulo de tomada é o linear. Pode-se observar que o fotógrafo desce até a altura da criança para fazer o enquadramento de forma que o leitor tenha um ponto de vista melhor em relação à visualização da fotografia. A regra dos terços é aplicada na composição do fotógrafo, em dois momentos: o buraco e a menina observando. A perspectiva, como na fotografia anterior, convida o leitor a se aprofundar na leitura da imagem. O primeiro plano traz o buraco na parede em evidência e, do lado oposto, a criança observando esse buraco. Textura presente na rusticidade do barro e da madeira. 
A intenção do fotógrafo, neste caso, foi mostrar a precariedade em que vivem os desabrigados de Terezina (PI), após a enchente. Se a imagem for observada em conjunto com os elementos de edição, a conclusão é de que, neste caso, a legenda apenas descreve a fotografia com informações levadas ao leitor pela própria imagem.

A última imagem da sequência selecionada por este artigo foi publicada na página C4 do caderno Cotidiano do dia 25 de maio, compondo a reportagem. Na fotografia (Figura 8) há pedaços de madeira, uma parede rústica, um espelho, aparentemente um retrovisor de carro e duas pessoas refletidas neste espelho.

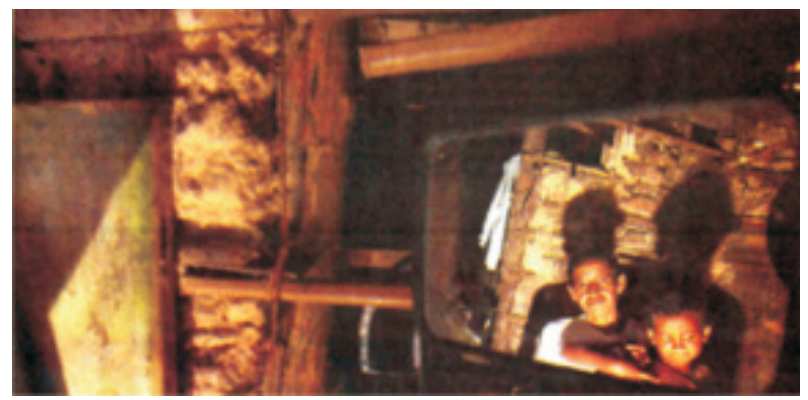

Figura 8 - Reflexo de Regina e de seu filho em espelho, numa casa de pau a pique Fotografia: Fernando Donasci

Fonte: Folha de S.Paulo - página C4 - 25/05/2009

O plano desta fotografia é o de detalhe, mostrando em primeiro plano, o espelho com a imagem refletida, as madeiras e a parede. Se a imagem for analisada como um todo, ou seja, o que o espelho reflete, o plano passa a ser o médio. O ângulo é linear, mais uma vez valorizando o sujeito. A regra dos terços é aplicada na composição do fotógrafo, enquadrando os elementos humanos em um dos pontos áureos. A textura, assim como na fotografia anterior, é bem presente, pela rusticidade do barro e madeira.

Há um contraste resultante da incidência de iluminação, chamado de contraste luminoso. A iluminação sugere a dramaticidade através das sombras invertidas, reforçando a sensação da situação sombria e precária 
em que estão vivendo os moradores. O reflexo de mãe e filho, no contexto de rusticidade da cena, leva o receptor a fazer uma leitura de que aquilo é o reflexo literal da situação dos moradores de Terezina (PI). "O espelho foi o que me chamou a atenção, por estar quebrado mostra que as pessoas que vivem ali tem dificuldades financeiras e também veio na cabeça como se um sonho de viver em paz estivesse faltando alguns pedaços compondo com a casa de barro."

\section{Considerações finais}

Pelo processo de desconstrução analítica, foi possível detectar, em todas as imagens analisadas neste artigo, que a intencionalidade de comunicação do repórter fotográfico Fernando Donasci foi valorizar o ser humano. Mesmo diante de cenários de destruição, nos quais centenas de famílias perderam todos os seus bens materiais, ele foi capaz de contextualizar a tragédia, dimensionar a tristeza da perda e representar o sentimento de dor sem expor a fragilidade e o desespero dos atingidos pelas enchentes. Pelo contrário, buscou valorizar as vítimas, respeitando seu sofrimento e prezando por sua dignidade. Suas imagens, ao mesmo tempo em que conotam perdas materiais, chamam a atenção para a esperança, solidariedade e perseverança das vítimas.

O próprio fotógrafo, em entrevista, afirmou ser proposital a valorização do ser humano na tentativa de aproximar o leitor do drama enfrentado pelos moradores dos estados do nordeste, especialmente o Maranhão e o Piauí. Sua postura diante da tragédia o aproxima do jornalismo humanizado, uma alternativa ao jornalismo de deadline, carregado de imagens chocantes para representar uma tragédia. No jornalismo humanizado, "ao invés de os profissionais se preocuparem com o imediatismo dos fatos e com a sua descrição podem transmitir aos seus

\footnotetext{
${ }^{6}$ Fernando Donasci. Entrevista concedida à Carolina Z. C. Mancuzo, por e-mail, em 27/06/2009.
} 
leitores quem são os agentes dos fatos, as pessoas que os vivenciaram, por meio do relato de histórias, experiências, conflitos e sentimentos". (ALVES; SEBRIAN, 2008). Nesse tipo de jornalismo, segundo os autores, "os protagonistas sociais não seriam meros figurantes das afirmativas dos especialistas, mas sim o ponto de partida e de chegada do fazer jornalístico". (ALVES; SEBRIAN, 2008).

A opção de Fernando Donasci pelo jornalismo humanizado pode ser melhor dimensionada pelas fotografias por ele próprio escolhidas (imune aos processos e filtros de edição do veículo em que trabalha) para a galeria de imagens postadas em sua página no Flickr $^{7}$, embora, ao contrário do jornal, essas fotografias demonstrem mais o contexto da enchente. Embora não seja objeto de estudo deste artigo, vale destacar que em uma rápida análise comparativa das fotografias publicadas pela Folha de S.Paulo com as postadas no Flickr, notase que o fotógrafo e o jornal fizeram escolhas diferentes.

Donasci afirmou que, na cobertura das enchentes no nordeste, produziu cerca de 300 fotografias por dia. Diz compreender que esse volume de imagens é um amplo universo para o editor de fotografia do jornal escolher apenas uma, duas ou três para publicação. Mas confessa que ao ver o jornal no dia seguinte "sempre acho que poderiam ter aproveitado melhor o material, publicar aquela outra..."8

Contudo, cada fotografia exibe implícita ou explicitamente a intencionalidade do fotógrafo que, no momento anterior ao clique, projeta uma intenção e procura exteriorizá-la na imagem capturada. As fotografias analisadas neste artigo não são flagrantes, são imagens pensadas, planejadas. Donasci teve tempo para produzi-las e contou com a conivência dos protagonistas, o que acentua ainda mais a certeza de sua intencionalidade.

As fotografias analisadas são do tipo que "sugerem", mas não "mostram" explicitamente a tragédia. Mesmo assim conseguem

\footnotetext{
${ }^{7}$ Página na internet utilizada para a publicação de fotografias.

${ }^{8}$ Fernando Donasci. Entrevista concedida à Carolina Z. C. Mancuzo, por e-mail, em 22/06/2009.
} 
impressionar o leitor. "Eu aprendi que a fotografia é feita em duas partes: a primeira quando faz o clique, e depois quando é observada com calma na edição, antes de enviá-la para o jornal". ${ }^{9}$

\section{Referências}

ALVES, Fabiana Aline; SEBRIAN, Raphael Nunes Nicoletti. Jornalismo humanizado: o ser humano como ponto de partida e de chegada do fazer jornalístico. CONGRESSO DE CIÊNCIAS SOCIAIS DA COMUNICAÇÃO NA REGIÃO SUL - INTERCOM SUL, 9., Guarapuava, 2008. Anais... Guarapuava: INTERCOM, 2008 .

BONI, Paulo César. Fotografia e mídia: da construção da imagem à veiculação de ideologias. Formas e Linguagens. Ijuí, ano 4, n.9, p.73-89, jan./jun. 2005.

CAMPOS, Fernanda Rodrigues; BONI, Paulo César. Fotojornalismo: os ataques do PCC nas páginas da Folha e do Estadão. Discursos Fotográficos, Londrina, v.3, n.3, p.55-80, 2007.

KOSSOY, Boris. Fotografia e história. São Paulo: Ática, 1989.

. Os tempos da fotografia: o efêmero e o perpétuo.

São Paulo: Ateliê Editorial, 2007.

MORETZSOHN, Sylvia. Jornalismo em tempo real: o fetiche da velocidade. Rio de Janeiro: Revan, 2002.

${ }^{9}$ Fernando Donasci. Entrevista por e-mail concedida à Carolina Z. C. Mancuzo, em 27/06/2009. 
SONTAG, Susan. Ensaios sobre a fotografia. Rio de Janeiro: Arbor, 1981.

SOUSA, Jorge Pedro. Uma história crítica do fotojornalismo Ocidental. Florianópolis: Letras Contemporâneas, 2004. 